\title{
Correction to: Worlds Apart? - The Challenges of Aligning Brand Value for NGO's
}

\author{
Karen Hand ${ }^{1} \cdot$ Rebecca Murphy ${ }^{2} \cdot$ Malcolm MacLachlan $^{2} \cdot$ Stuart Colin Carr $^{3}$ \\ Published online: 10 November 2021 \\ ๑) Springer-Verlag GmbH Germany, part of Springer Nature 2021
}

\section{Correction to: International Review on Public and Nonprofit Marketing https://doi.org/10.1007/s12208-021-00312-4}

Correcting the affiliation on the paper for the below:

Professor Malcolm MacLachlan and Dr Rebecca Murphy are both affiliated with Department of Psychology, Assisting Living \& Learning Institute, Maynooth University, Kildare, Ireland.

Publisher's note Springer Nature remains neutral with regard to jurisdictional claims in published maps and institutional affiliations.

The original article can be found online at https://doi.org/10.1007/s12208-021-00312-4

Karen Hand

karenhand9@gmail.com

$1 \quad$ Strategy \& Research, Dublin, Ireland

2 Department of Psychology, Assisting Living \& Learning Institute, Maynooth University, Kildare, Ireland

3 Industrial and Organisational Psychology Programme, School of Psychology, Massey

University, Massey, New Zealand 